\title{
Embrio Destinasi Wisata Religi Baru: Identifikasi Komponen 3A Berbasis Wisata Ziarah Desa Balun, Lamongan
}

\author{
Indra P P Salmon ${ }^{1}$, Ismail ${ }^{2}$, Wahyu E Pujianto ${ }^{3}$, Fitroh Nadyah ${ }^{4}$ \\ Universitas Bhayangkara Surabaya ${ }^{1,2,4}$ \\ Sekolah Tinggi Agama Islam Al-Akbar Surabaya ${ }^{3}$
}

Korespodensi dengan Penulis:

Indra P P Salmon: Telp: 0895376503676

E-mail: indrapratamaps29@gmail.com

Keywords:

Religious Tourism,

Cultural

Attractions,

Pancasila Village,

Balun, Lamongan

Regency

\begin{abstract}
This study aims to examine the readiness and feasibility of supporting components in the midst of the designation of the Balun Village as the Pancasila Village and the Religious Tourism District of Lamongan Regency. Cultural attractions offered are the Mbah Alun Graveyard Site and the value of pluralism of religious community life in Balun Village. The study used a qualitative method with a descriptive analytic and participatory rural appraisal (PRA) approach. Data collection techniques in the form of narratives sourced from several informants, secondary statistical data, and field documentation. The results of the study indicate that the readiness represented in component $3 A$, namely: Attractions, in the form of cultural attractions either physical or tangible (pilgrimage sites) and non-physical or intangible (values of pluralism of society / diversity and religious festivals) have been owned and run for decades; Accessibility in the form of distance to Balun Village from strategic points relatively close $(2-5 \mathrm{~km})$ and road infrastructure conditions, as well as; Amenities and additional supporting elements in the form of services and other supporting services available such as accommodation for tourists, restaurants and culinary centers, souvenir centers, transportation points and access close to the main road. Another development that needs to be done is improvement in terms of accessibility considering the opportunity of arrival at the Balun Village Pilgrimage Site jumped dramatically on certain religious holidays.
\end{abstract}

Kata Kunci:

Wisata Religi, Atraksi Budaya, Desa Pancasila, Balun, Lamongan 
dimiliki dan berjalan selama berpuluh tahun; Kedua berupa aksesibilitas, yakni jarak menuju Desa Balun dari titik-titik strategis yang relatif dekat (2$5 \mathrm{~km}$ ) dan kondisi infrastuktur jalan; Ketiga berupa amenitas dan elemen pendukung tambahan berupa adanya layanan dan pendukung lainnya yag tersedia seperti akomodasi/penginapan bagi wisatawan, rumah makan dan pusat kuliner, pusat oleh-oleh, titik transportasi dan akses yang dekat dengan jalan utama. Pengembangan lain yang perlu dilakukan adalah perbaikan dari segi aksesibilitas mengingat peluang kedatangan di Situs Ziarah Desa Balun melonjak secara drastis pada hari-hari besar keagamaan tertentu.

\section{PENDAHULUAN}

Sektor wisata masih menjadi sektor andalan yang mampu meningkatkan pendapatan daerah Kabupaten Lamongan, khususnya wisata religi (Dinas Pariwisata Kabupaten Lamongan, 2020). ${ }^{1}$ Di Kabupaten Lamongan, pengunjung atau wisatawan yang datang ke lokasi wisata religi konsisten tinggi dan mencapai $>50 \%$ dari seluruh wisatawan di Kabupaten Lamongan. Untuk satu objek wisata religi saja, kontribusi sektor tersebut mencapai Rp. 644.100.000,00/tahun (Dinas Pariwisata Kabupaten Lamongan, 2020). ${ }^{2}$ Artinya bahwa di Kabupaten Lamongan, sektor wisata religi masih berpotensi dan sangat menarik untuk terus dikembangkan sebagai alternatif peningkatan pendapatan daerah.

Desa Balun sendiri merupakan salah satu desa yang ditetapkan sebagai kawasan strategis oleh pemerintah daerah dan memiliki potensi utama berupa wisata religi (Naskah Akademik RTRW Kabupaten Lamongan, 2020)3. Desa tersebut terletak di Kecamatan Turi Kabupaten Lamongan dengan luasan mencapai 5,61 $\mathrm{km}^{2}$ atau $11,52 \%$ dari seluruh luasan di Kecamatan Turi dan menjadikan Desa Balun merupakan desa terluas serta degan ketinggian wilayah 6 mdpl (Kecamatan Turi dalam Angka, 2018) ${ }^{4}$. Untuk jarak masing-masing titik pusat, yakni antara Desa Balun ke Pusat Kecamatan Turi dan Kabupaten Lamongan yakni 5 km (Kecamatan Turi dalam Angka, 2018)5. Letaknya yang dekat dengan Kabupaten Lamongan dan pusat keramaian menjadikan kawasan ini semakin strategis untuk dilakukan pengembangan lebih lanjut sebagai kawasan wisata alternatif.

Secara administratif, kewilayahan, dan kependudukan, Desa Balun terbagi atas 2 dusun (Dusun Balun dan Dusun Ngangkrik), 4 RW, dan 21 RT (Kecamatan Turi dalam Angka, 2018). Untuk pembagian wilayah, RT, dan RW, Dusun Balun terdiri dari 3 RW dan 18 RT sedangkan Dusun Ngangkrik terdiri dari 1 RT dan 3 RW. Dengan jumlah penduduk 4.952 orang (yang terdiri dari 2.488 laki-laki dan 2.464 perempuan), jumlah kepala keluarga

${ }^{1}$ Dinas Pariwisata Kabupaten Lamongan. (2020). Pemerintah Kabupaten Lamongan.

2 Ibid.

3 Naskah Akademik Rencana Tata Ruang dan Tata Wilayah Kabupaten Lamongan. (2020). Pemerintah Kabupaten Lamongan.

4 Kecamatan Turi dalam Angka 2018. (2018). BPS Kabupaten Lamongan.

${ }^{5}$ Ibid. 
(KK) mencapai 1.103 KK dan kepadatan penduduk di Desa Balun mencapai 883 penduduk $/ \mathrm{km}^{2}$.

Luas sebesar 5,61 km², wilayah Desa Balun didominasi oleh kawasan pertanian seluas 495 ha dengan produktivitas pertanian sebanyak 3.686,18 ton per tahun. Di luar pertanian, Desa Balun juga memiliki kekuatan yang pada saat ini tengah dikembangkan berupa kawasan wisata religi dan menggunakan daya tarik latar belakang kepercayaan masyarakat yang heterogen. ${ }^{6}$ Kawasan wisata religi tersebut berupa keberadaan situs Mbah Alun yang merupakan pendiri desa yang sejak lama telah menanamkan kehidupan toleransi antar umat beragama. Hal ini yang kemudian menjadikan masyarakat di Desa Balun sangat menjunjung tinggi bentuk-bentuk kerukunan umat beragama dan nilai-nilai toleransi.

Gambar 1. Peresmian Desa Balun sebagai Kawasan Wisata Religi

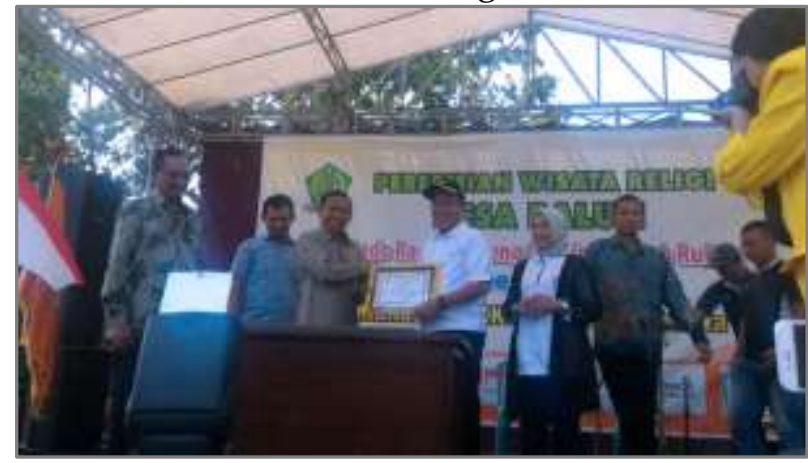

Sumber: Dokumentasi (2019)

Pluralisme masyarakat di Desa Balun menjadi satu ciri khas yang kemudian terkenal dengan sebutan Desa Pancasila. Selain masyarakat yang dikenal sangat menjaga nilai-nilai toleransi dan kebebasan beribadah menurut kepercayaan masing-masing, Desa Balun juga memiliki situs keagamaaann dan kawasan peribadatan serta festival kebudayaan dan keagamaan. Bahkan dalam aktivitas hari besar keagamaan atau kegiatan berbasis kebudayaan, keterlibatan dan partisipasi masyarakat cukup tinggi dan tidak memandang agama dari segi pluralisme. Bagi masyarakat lokal, hal ini dianggap biasa dan memang sudah sewajarnya. Namun permasalahan yang tidak disadari adalah keunikan ini merupakan satu keunggulan kompetitif desa untuk dapat memberikan peluang dampak ekonomi terhadap masyarakat ketika terdapat upaya pengembangan dalam bentuk integrasi spasial kawasan wisata di Kabupaten Lamongan. Dengan kata lain bahwa atraksi budaya mampu menjadi salah satu daya tarik wisatawan baik domestik maupun mancanegara dalam mendapatkan pengalaman baru. ${ }^{7}$

Di era tantangan pembangunan seperti saat ini, kompetisi selalu menjadi alasan untuk mendorong kemajuan. Guna menjawab tantangan tersebut, upaya yang dapat dilakukan

${ }^{6}$ Khoirul Ulum, "Budaya Toleransi: Studi Living Islam di Desa Balun, Lamongan", Living Islam: Journal of Islamic Discourses, Vol. 2, No. 1, 2019. hlm. 143-168.

7 Ariyanto, Ekonomi Pariwisata, (Jakarta: Penerbit Rineka Cipta, 2006); Nobert Vanhove, The Economics of Tourism Destinations, (Great Britain: Elsevier Butterworth-Heinemann, 2005). 
yakni dengan membuat bentuk-bentuk inovasi. Alasan dari adanya inovasi tersebut adalah adanya upaya mengatasi tantangan sekaligus peningkatan nilai tambah suatu produk yang nantinya turut berdampak pada kinerja pemasaran, kelompok, dan organisasi atau perusahaan hingga akhirnya meningkatkan daya saing dalam kompetisi. ${ }^{8}$ Hal ini juga termasuk dalam upaya pengembangan wisata dan keunikan yang ada di Desa Balun.

Desa Balun yang telah dikenal memiliki embrio wisata religi, corak masyarakat yang heterogen, dan atraksi budaya sangat berpeluang dalam meningkatkan kualitas sosial ekonomi masyarakat dengan melakukan pengembangan khususnya di bidang pariwisata berbasis budaya. Keunggulan yang ditawarkan yakni berupa atraksi wisata budaya existing didukung oleh keberadaan aksebilitas strategis kawasan wisata ziarah di Kabupaten Lamongan. Selain itu, adanya aksebilitas ini juga didukung oleh keberadaan komponen pelengkap lainnya seperti akomodasi penginapan, pusat kuliner, pusat penjualan oleh-oleh, serta kelengkapan lainnya yang tersedia di Kabupaten Lamongan.

Sebagaimana dingkapkan oleh Holloway bahwa pariwisata harus mengandung komponen 3A antara lain attraction, accessibility, dan amenity. Attraction atau atraksi wisata merupakan komponen mutlak yang harus ada dalam aktivitas kepariwisataan. ${ }^{9}$ Atraksi wisata terdiri dari atraksi alam, atraksi buatan, dan atraksi budaya. Desa Balun sendiri telah memiliki atraksi budaya berupa situs ziarah yang dikenal dengan Makam Mbah Alun. Selain itu juga nilai pluralisme di dalamnya merupakan aspek pendukung kebudayaan masyarakat lokal dalam aktivitas kepariwisataan. Accessibility atau aksesibilitas merupakan akses yang dapat digunakan menuju situs budaya di Desa Balun terutama jarak dan kondisi kelayakan akses. Terhitung bahwa jarak pusat wisata dengan pusat kota dan simpul transportasi hanya sejauh $2-4 \mathrm{~km} .{ }^{10}$

Dengan kata lain bahwa sangat mudah dan memungkinkan ketika wisatawan ingin menuju situs budaya di Desa Balun. Amenitas sendiri merupakan komponen pelengkap termasuk rumah ibadah, ketersediaan penginapan, rumah makan, dan komponen lainnya yang dibutuhkan oleh pengunjung atau wisatawan dalam melakukan perjalanan wisata. Urgensi kajian ini adalah melakukan pemetaan dan identifikasi berkaitan dengan kelayakan kawasan wisata ziarah di Desa Balun sebagai alternatif destinasi wisata ziarah berbasis

8 Seyedeh Khadijeh Taghizadeh dan Syed Abidur Rahman "The Effect of Service Product Innovation Management on Market Performance," International Journal of Business an Innovation, Vol. 1, No. 1, 2013. hlm. 1-15; Rosli, M.M, \& Syamsuriana, S., "The Impact of Innovation on The Performance of Small and Medium Manufacturing Enterprises: Evidence of Malaysia", Journal of Innovation Management in Small and Medium Enterprises, Vol. 2, No. 2, 2013; Tamayo, J.A., Garcia, J.E.R., dan Roman, J.A., “Do Innovation and Cooperation Influence SMEs Competitiveness? Evidence from The Andalusian Metal-Mechanic Sector", Innovar Journal, Vol. 25, No. 5, 2014. hlm. 101-115.

${ }^{9}$ Holloway, J., Humphreys, C., dan Davidson, R., The Business of Tourism, 8th Edition, (England: Pearson Education Limited, 2009).

${ }^{10}$ Google Maps (diakses 2020). 
atraksi budaya. Selain itu juga dilakukan pemetaan lanjutan dalam kaitannya dengan integrasi kawasan wisata sebagai upaya mengembangkan sektor kepariwisataan di Kabupaten Lamongan.

Kajian terdahulu seputar wisata religi Desa Balun telah dilakukan oleh beberapa peneliti. Pertama, kajian dilakukan Ismail dkk dengan judul "Desain Persatuan dan Kesatuan sebagai Ikon Desa Wisata Religi di Desa Balun Kecamatan Turi Kabupaten Lamongan Jawa Timur". ${ }^{11}$ Kajian ini berbasis sejarah dan sosio-kultural dengan menggunakan pendekatan kualitatif. Substansi dari kajian yang dilakukan oleh Ismail dkk yakni menjelaskan tentang latar belakang terbentuknya Desa Balun, ciri khas masyarakat yang ada di Desa Balun, dan dasar desain strategi ditetapkannya Desa Balun sebagai Desa Pancasila. Hasil penelitian berupa Desa Balun telah menjadi embrio dalam kaitannya dengan upaya pengembangan sebagai wisata religi.

Penelitian selanjutnya dilakukan oleh Alfattah dengan judul “Tradisi Upacara OgohOgoh". Kajian ini berlatar sosiologis seputar kehidupan kerukunan sosial antar umat beragama di Desa Balun. Kajian ini menggunakan pendekatan kualitatif deskriptif. Hasil penelitian yang dilakukan Alfattah menunjukkan bahwa: pertama, tradisi upacara ogohogoh di Desa Balun memiliki makna yang diyakini oleh masyarakat desa berupa pengusir keburukan dan roh jahat di Desa Balun; kedua, tradisi upacara ogoh-ogoh dilaksanakan melalui lima tahapan yang secara keseluruhan memiliki makna mempererat persatuan dan kesatuan, serta; ketiga, tradisi upacara ogoh-ogoh merupakan salah satu daya tarik di Desa Balun dalam upaya pengembangan toleransi antar umat beragama di Indonesia. ${ }^{12}$

Penelitian ketiga yakni dilakukan oleh Bettaliyah dan Mubin dengan judul "Peta Desa Wisata Budaya sebagai Pembentuk Citra Desa Balun Kecamatan Turi Kabupaten Lamongan". Penelitian tersebut berlatar deskripsi pengunjung atau wisatawan situs religi di Desa Balun. Metode penelitian menggunakan pendekatan deskriptif kualitatif. Hasil penelitian menujukkan bahwa heterogenitas kepercayaan masyarakat di Desa Balun dan kehidupan yang harmonis merupakan alasan kuat mengapa desa tersebut banyak dikunjungi. Selain itu juga penelitian ini menyimpulkan adanya kebutuhan peta desa sebagai kebutuhan pelengkap dari elemen wisata di Desa Balun. ${ }^{13}$

Berdasarkan penelitian terdahulu, kebaruan dari penelitian kali ini adalah memberikan perspektif yang lebih detail dalam kaitannya dengan upaya menjadikan Desa Balun sebagai kawasan wisata religi potensial. Kekurangan penelitian terdahulu yang kami ambil adalah kami belum melihat adanya pemetaan elemen pelengkap yang harus

11 Ismail, Titofianti, A. A., dan Nurany, F., “Desain Persatuan dan Kesatuan sebagai Ikon Desa Wisata Religi di Desa Balun Kecamatan Turi Kabupaten Lamongan Jawa Timur," Governance: Jurnal Manajemen dan Kebijakan Publik, Vol. 9, No. 1, 2019. hlm. 57-63.

12 Alfattah, M. S., “Tradisi Upacara Ogoh-Ogoh”, Jurnal Antro, Vol. 4, No. 3,2017. hlm. 289-300.

13 Bettaliyah, A. A., \& Mubin, M., "Peta Desa Wisata Budaya sebagai Pembentuk Citra Desa Balun Kecamatan Turi Kabupaten Lamongan", Senasif, Vol. 2, No. 1, 2018. H; 1448-1454. 
dijabarkan ketika satu kawasan ditetapkan sebagai kawasan wisata. Sebagian besar hanya mendeskripsikan kondisi internal yang ada di Desa Balun. Lebih lanjut lagi bahwa kontribusi dari tulisan ini adalah mengulas secara teknis seputar elemen-elemen kawasan wisata yang ada di Desa Balun (berupa elemen 3A atau attraction, accessibility, dan amenity) sebagai upaya pendukung dan dasar kuat nantinya ketika Desa Balun ditetapkan sebagai kawasan wisata religi alternatif di Kabupaten Lamongan.

\section{METODE}

Kajian yang dilakukan menggunakan metode kualitatif dengan pendekatan deskriptif analitik dan participatory rural appraisal (PRA). Metode kualitatif merupakan prosedur penelitian yang berupaya menghasilkan data deskriptif seperti catatan lisan dan perilaku objek amatan yang dilanjutkan dengan ekplorasi makna. ${ }^{14}$ Sementara itu, pendekatan deskriptif analitik merupakan metode yang berupaya untuk mendapatkan data baik berbentuk angka atau dokumentasi dengan pemaknaan mendalam. Untuk pendekatan PRA sendiri, bertujuan untuk meningkatkan aspek-aspek pemberdayaan dan peningkatan partisipasi masyarakat yang bermuara pada keterlibatan masyarakat dalam satu program. ${ }^{15}$

Teknik pengumpulan data terdiri dari wawancara informal mendalam (dengan pemerintah desa dan beberapa informan kunci), data statistik tentang topik yang ditulis (monograf desa dan data BPS), dokumentasi lapangan, dan observasi yang dilakukan di Desa Balun. Pengolahan data dilakukan dalam bentuk kompilasi data-data hasil observasi lapangan, pemilahan atau reduksi data yang relevan dengan topik penelitian, dan penyusunan narasi hasil penelitian. Di samping itu, pada saat pelaksanaan riset lapangan peneliti mendorong masyarakat dalam upaya menggali permasalahan desa (berdasarkan perspektif masyarakat, pemerintah desa, dan tim ahli), merumuskan alternatif solusi, serta membuat kesepakatan bersama dalam kaitannya dengan aktivitas kepariwisataan yang ada di Desa Balun Kecamatan Turi Kabupaten Lamongan.

\section{PEMBAHASAN}

Guna menjadikan Desa Balun sebagai destinasi wisata, maka perlu dipastikan bahwa unsur-unsur elemen pendukung existing telah dimiliki, dipersiapkan, dan direvitalisasi (sebagai upaya lanjutan optimalisasi kawasan wisata). Sebagai tindak lanjut, maka harus

${ }_{14}$ Cresswell, J. W., Research Design: Qualitative, Quantitative, and Mixed Methods Approaches (4th edition), (California: SAGE Publication Inc, 2013); Taylor, S. J., Bogdan, R., dan DeVault, M., Introduction to Qualitative Research Methods: A Guidebook and Resource, (New Jersey: John Wiley \& Sons, 2015).

15 Chambers, R., PRA (Participatory Rural Appraisal): Memahami Desa secara Partisipatif (edisi terjemahan), Yogyakarta: Kanisius, 1996; Supriatna, A., "Relevansi Metode Participatory Rural Appraisal dalam Mendukung Implementasi Undang-Undang Pemerintahan Desa", Jurnal Lingkar Widyaiswara, Vol. 1, No. 1, 2014. hlm. 39-45. 
dilakukan pemetaan terhadap kawasan wisata berkaitan komponen-komponen yang dimiliki. Tujuan utamanya adalah mengukur seberapa jauh kesiapan kawasan wisata di Desa Balun dan melakukan proyeksi terhadap peluang di masa mendatang di sektor kepariwisataan. Sebagaimana dingkapkan Holloway et al (2009) bahwa prasyarat kawasan wisata adalah keberadaan komponen 3A yang terdiri dari attraction, accessibility, dan amenity. ${ }^{16}$ Produk pariwisata sendiri sangatlah luas, meliputi barang (tangible) dan jasa (intangible) yang menjadi kunci dan mampu memberikan pengelaman bagi pengunjung atau wisatawan dengan batas wilayah tertentu. ${ }^{17}$ Berdasarkan hal tersebut, maka perlu untuk memetakan dan mendeskripsikan elemen-elemen kawasan wisata ziarah di Desa Balun sebagai pijakan awal.

\section{Atraksi Wisata}

Atraksi wisata yang ada di Desa Balun tergolong dalam jenis atraksi budaya. Atraksi budaya yang menjadi daya tarik bagi wisatawan berupa situs ziarah makam Mbah Alun dan kawasan peribadatan yang berada dalam satu lingkungan dengan situs ziarah. Sekilas bagi mayoritas warga lokal hal ini merupakan kondisi yang biasa saja. Namun sangat kontras ketika masyarakat dari luar Desa Balun dan Kabupaten yang datang. Akan ada semacam anggapan bahwa sangat kontrakdiktif antara Pulau Jawa dengan keberagaman dan kemajemukan masyarakat. Artinya, baik secara nyata (riil) dan animo yang beredar bahwa masih ada anggapan bahwa Pulau Jawa diindikasikan sebagai pulau dengan mayoritas penduduk beragama Islam dan masyarakat yang beragama lainnya sangat jarang. Kalaupun ada, jumlahnya pun sangat sedikit. Di Desa Balun sendiri, terdapat ratusan masyarakat yang beragama non-Islam (Nasrani dan Hindhu) dengan tempat peribadatan yang notabene sangat layak bagi masyarakat. Letak antara situs ziarah dengan kawasan peribadatan (masjid besar, gereja, dan pura) hanya berjarak kurang dari 40 meter. Masingmasing situs dan temat peribadatan saling terkoneksi satu sama lain dan terletak satu kompleks jalan.

Selain situs ziarah, adanya kultur pluralism yang telah diimplementasikan selama bertahun-tahun lamanya menjadi daya tarik tersendiri untuk dapat ditawarkan. Nuansa baru yang membedakan Desa Balun dengan Kawasan Wisata lainnya di Pulau Jawa adalah kehidupan harmonis antar masyarakat dengan beragam latar belakang agama yang berbeda dan sangat kontras terlihat pada saat momen hari besar keagamaan. Adanya nuansa tersebut mengalir dalam kehidupan serta diwujudkan dalam bentuk sikap keramahan pada

16 Op.cit. Holloway, J., Humphreys, C., \& Davidson, R., The Business of Tourism, 8th Edition, (England: Pearson Education Limited, 2009).

17 Benur, A. M., \& Bramwell, B., "Tourism Product Development and Product Diversification in Destinations", Tourism Management, Vol. 50, 2015. hlm. 213-224; León, C. J., Hernández, J. M., \& González, M., "Economic Welfare, The Environment and The Tourist Product Life Cycle”, Tourism Economics, Vol. 13, No. 4, 2007. hlm. 583-601; Meler, M., \& Cerović, Z., "Food Marketing in The Function of Tourist Product Development", British Food Journal, Vol. 105, No. 3, 2003. hlm. 175-192. 
pemeluk agama lain, baik di dalam lingkungan Desa Balun maupun pada pengunjung yang berasal dari luar Desa Balun. Dalam konteks kepariwisataan, kultur ini merupakan salah satu bagian dari konsep keramahan wisata atau tourism hospitality concept yang menjadi keunggulan kompetitif bagi kawasan wisata. Konsep ini terjadi antara tuan rumah atau penyedia jasa dengan tamu atau wisatawan. Jika sambutan dan suasana yang ditawarkan di kawasan wisata tergolong baik, maka peluang memberikan kepuasan dan pengalaman bagi tamu atau wisatawan pun semakin tinggi. Sebagaimana diungkapkan bahwa hospitality memegang peranan kunci dalam upaya peningkatan kepuasan wisatawan untuk bisa mendapatkan pengalaman kunjungan. ${ }^{18}$

Gambar 2. a) Situs Makam Mbah Alun; b) Akses Masuk Wisata Ziarah; c,d,e) Tempat Peribadatan di Desa Balun (GKJW Lamongan Wilayah Desa Balun; Pura Sweta Maha Suci; Masjid Miftahul Huda)

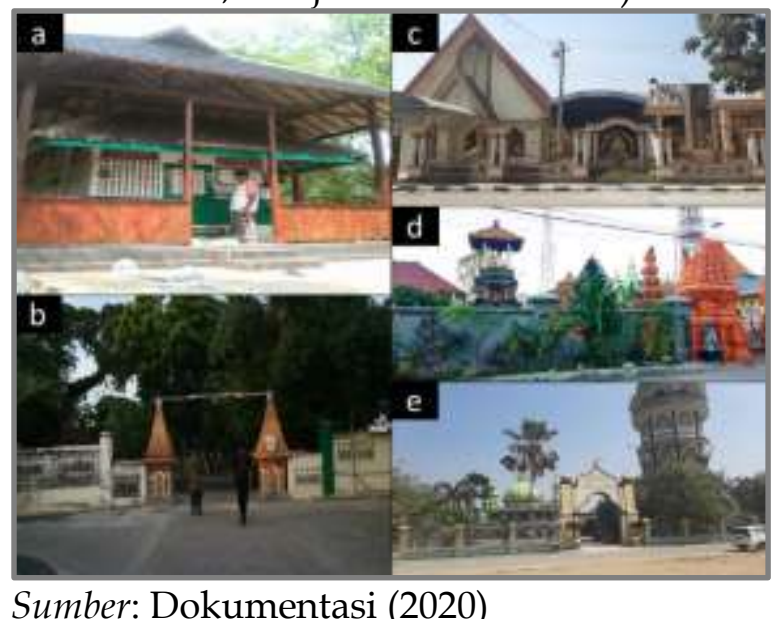

\section{Aksesibilitas Kawasan Wisata}

Aksesibilitas baik dari perspektif keberadaan secara alamiah maupun strategi pengembangan spasial memiliki peranan yang sangat penting dalam mendukung kesuksesan pembangunan sektor pariwisata. Aksesibilitas strategis menjadi salah satu kata kunci yang memiliki dampak signifikan terhadap pembangunan sektor pariwisata. Aksesibilitas tersebut termasuk jarak wisatawan dalam mencapai titik pusat kawasan wisata, infrastruktur, dan konektivitas antara titik wisata dengan titik-titik strategis lainnya. ${ }^{19}$ Kebutuhan lainnya berkaitan dengan manajemen dan pemetaan akses adalah

18 Gomezelj, D. O., "A Systematic Review of Research on Innovation in Hospitality and Tourism", International Journal of Contemporary Hospitality Management, Vol. 28, No. 3, 2016. hlm. 516558; Litvin, S., Goldsmith, R., \& Pan, B.,"A Retrospective View of Electronic Word-of- Mouth in Hospitality and Tourism Management", Journal of Contemporary Hospitality Management, Vol. 30, No. 1, 2018. hlm. 313-325.

19 Chin, C. Law, F. Y., Lo, M. C., \& Ramayah, T, “The Impact of Accessibility Quality and Accommodation Quality on Tourists' Satisfaction and Revisit Intention to Rural Tourism Destination in Sarawak: The Moderating Role of Local Communities' Attitude", Global Business and Management Research: An International Journal, Vol. 10, No. 2, 2018. hlm. 115-127; Ewen, C. J., Hoffer, M. R., Capobianco, M. C., \& Doucette, R. M., Community-Based Inclusion: Promoting Rural Tourism Through 
memberikan layanan maksimal melalui rekayasa jarak yang memungkinan wisatawan bisa lebih lama berada di lokasi wisata sehingga mampu mendapatkan pengalaman baru sebanyak-banyaknya.

Gambar 3. a) Jarak Akses Menuju Desa Balun (dari Pusat Ibukota); b) Gapura Akses

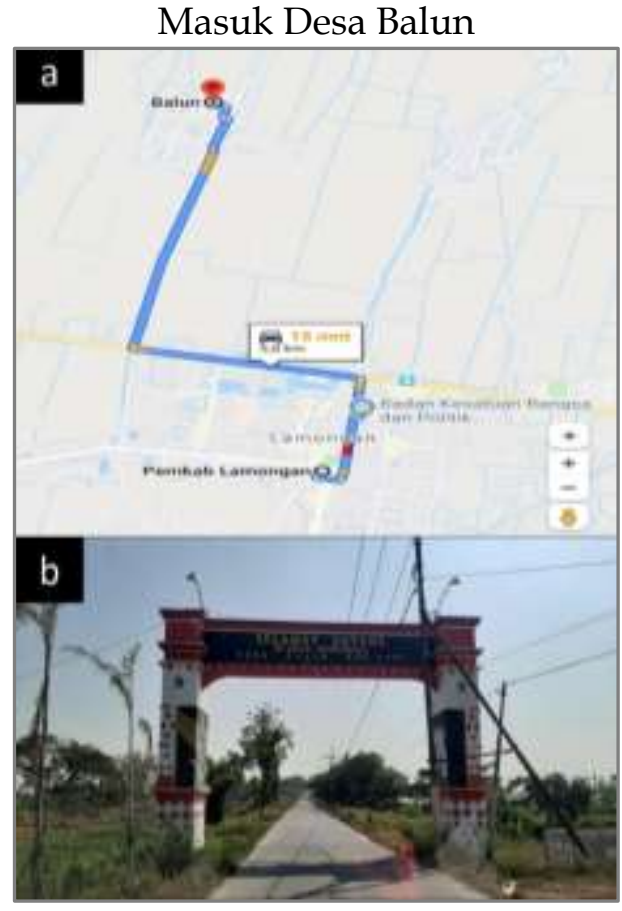

Sumber: Dokumentasi (2020)

Untuk menuju titik kawasan wisata di Desa Balun, perlu mempertimbangkan 2 hal yakni: pertama, infrastruktur akses, dan; kedua, pola akses menuju titik wisata di Desa Balun. Urgensi ketersediaan infrastuktur akses merupakan aspek yang penting dalam menilai layak tidaknya komponen pendukung wisata dalam menciptakan destinasi wisata yang unggul mengingat wisatawan pengunjung menggunakan alat transportasi yang sangat beragam. Di samping itu, prasarana yang baik akan menciptakan citra baik atau buruk di mata wisatawan. Ketersediaan lainnya berupa pola akses menuju titik pusat atraksi wisata budaya di Desa Balun. Jarak antara titik pusat atraksi wisata dengan kawasan-kawasan strategis terletak pada kisaran jarak 2-5 km. Beberapa kawasan strategis tersebut adalah jalan raya utama, pusat ibukota Kabupaten Lamongan simpul transportasi (Terminal Bus Lamongan dan Stasiun Kereta Api), pusat kuliner, dan pusat oleh-oleh di Kabupaten Lamongan.

Accessibility in Cuenca, Ecuador. Worcester Polytechnic Institute: Interactive Qualifying Projects, 2019; Sanchez, P. S., \& Dorta, A. V., "Drivers of Airport Scheduled Traffic in European Winter Tourism Areas: Infrastructure, Accessibility, Competition and Catchment Area", Journal of Transport Air Management, Vol. 81, 2019. hlm. 1-11. 


\section{Amenitas beserta Komponen Tambahan}

Sebagai pelengkap, maka 2 komponen lainnya dalam aktivitas kepariwisataan harus diperhitungkan yakni komponen amenity dan anciliary. Amenity atau amenitas merupakan seluruh sarana prasarana yang berada di sekitar pusat wisata tujuan. Sarana prasarana ini terdiri dari penginapan/hotel, rumah makan, simpul transportasi, pusat kuliner, pusat oleholeh, dan agen perjalanan. Terdapat kurang lebih 7 hotel di Kabupaten Lamongan, 2 simpul transportasi (terminal bus dan stasiun kereta api), dan pusat kuliner yang ada di Pusat Kabupaten Lamongan. Sementara untuk anciliary atau komponen layanan tambahan yang masuk dalam kategori amenity, Desa Balun telah ditetapkan sebagai Desa Pancasila yang artinya sangat potensial untuk dikembangkan sebagai destinasi wisata baru di Kabupaten Lamongan dengan branding tersebut.

Tabel 1. Amenitas dan Komponen Pelengkap Situs Budaya Desa Balun

\begin{tabular}{c|c|c} 
No & $\begin{array}{c}\text { Amenitas/Komponen } \\
\text { Pelengkap }\end{array}$ & Jarak ke Titik Pusat Wisata \\
\hline $\mathbf{1}$ & $\begin{array}{c}\text { Pusat Ibukota (Alun-Alun, } \\
\text { Pusat Pemerintahan, dan } \\
\text { Masjid Agung) }\end{array}$ & $5 \mathrm{~km}$ \\
\hline $\mathbf{2}$ & Pusat Kuliner & $\begin{array}{c}3-5 \mathrm{~km} \text { (bervariasi, tersebar di } \\
\text { sekitar pusat ibukota } \\
\text { kabupaten) }\end{array}$ \\
\hline $\mathbf{3}$ & Pusat Oleh-Oleh & $\begin{array}{c}3-5 \mathrm{~km} \text { (bervariasi, tersebar di } \\
\text { sekitar pusat ibukota } \\
\text { kabuupaten) }\end{array}$ \\
\hline $\mathbf{4}$ & Jalan Utama & $2 \mathrm{~km}$ \\
\hline $\mathbf{5}$ & Terminal Bus Lamongan & $4 \mathrm{~km}$ \\
\hline $\mathbf{6}$ & Stasiun Kereta Api Lamongan & $3 \mathrm{~km}$ \\
\hline $\mathbf{8}$ & Agen Perjalanan & $4 \mathrm{~km}$ \\
\hline & Hotel/Penginapan & $\begin{array}{c}2-5 \mathrm{~km} \text { (bervariasi, terdapat 7 } \\
\text { hotel yang tersebar di Kota } \\
\text { Lamongan) }\end{array}$
\end{tabular}

Sumber: Google Maps (diolah, 2020)

Pada dasarnya, Kabupaten Lamongan telah memiliki komponen pelengkap dalam kaitannya dengan persiapan pengembangan Desa Balun sebagai destinasi wisata budaya. Beberapa komponen tersebut merupakan elemen yang seringkali digunakan dan dibutuhkan oleh para wisatawan dalam berkunjung dan mendapatkan pengalaman baru. Mengingat jarak Desa Balun yang dekat dengan Pusat Kabupaten Lamongan, maka peluang pengembangan atraksi budaya sebagai embrio wisata baru semakin besar. Komponen amenitas dan pendukung lainnya dengan jarak yang relatif dekat (berkisar antara 2-5 km) mampu menjadi keunggulan akses yang mampu ditawarkan di tengah upaya rencana pengembangan kawasan wisata. Selain aspek jarak dan geografi kewilayahan, stabilitas sosial masyarakat juga menjadi aspek pendukung dalam konteks keamanan wilayah. Hal ini 
tampak dari kajian yang menyebutkan bahwa meskipun masyarakat di Desa Balun memiliki struktur kepercayaan yang heterogen, hal ini bukan menjadi halangan untuk hidup rukun dan toleran dalam kehidupan antar umat beragama di tengah maraknya isu konflik antar umat beragama (Alfattah, 2018; Bettaliyah dan Mubin, 2017) ${ }^{20}$. Temuan tersebut semakin meyakinkan bahwa keamanan khususnya masyarakat majemuk yang mampu menghargai masyarakat lain dengan keyakinan yang berbeda.

\section{KESIMPULAN}

Melalui situs atraksi budaya berupa Makam Mbah Alun, hal tersebut merupakan trigger baru dalam pengembangan sektor kepariwisataan di Kabupaten Lamongan. Sejak diresmikannya Desa Balun sebagai Kawasan Wisata Religi pada tahun 2019, artinya perlu dilakukan persiapan berkaitan dengan komponen dan elemen pendukung destinasi wisata. Dalam kajian ini, kajian dilakukan pada kesiapan 3 komponen yakni atraksi budaya berupa situs dan nilai pluralisme di Desa Balun yang telah ada selama puluhan tahun; aksesibilitas berupa akses jarak dan kondisi jalan menuju Desa Balun dengan kondisi yang cukup dekat dengan titik pusat wisata serta membutuhkan upaya pengembangan, dan; amenitas beserta komponen pendukung berupa keberadaan kelengkapan seperti simpul transportasi, pusat kuliner, pusat souvenir (oleh-oleh) di Kabupaten Lamongan. Hasil secara keseluruhan menunjukkan bahwa posibilitas pengembangan Desa Balun sebagai kawasan wisata religi sangat memungkinkan. Hanya saja, diperlukan upaya pengembangan khususnya dari segi aksesibilitas melalui peran antara pemerintah, ahli, dan masyarakat.

\section{UCAPAN TERIMA KASIH}

LPPM Universitas Bhayangkara.

\section{DAFTAR PUSTAKA}

Alfattah, M. S., “Tradisi Upacara Ogoh-Ogoh”, Jurnal Antro, Vol. 4, No. 3, pp. 289-300, 2017. http:/ /journal.unair.ac.id/download-fullpapers-aun2299ea3239full.pdf

Ariyanto, Ekonomi Pariwisata, Jakarta: Penerbit Rineka Cipta, 2006.

Benur, A. M., \& Bramwell, B., “Tourism Product Development and Product Diversification in Destinations", Tourism Management, Vol. 50, pp. 213-224, 2015. https://doi.org/10.1016/j.tourman.2015.02.005

Bettaliyah, A. A., \& Mubin, M., "Peta Desa Wisata Budaya sebagai Pembentuk Citra Desa Balun Kecamatan Turi Kabupaten Lamongan", Senasif, Vol. 2, No. 1, pp. 1448-1454, 2018. https://jurnalfti.unmer.ac.id/index.php/senasif/article/view/166/138

${ }^{20}$ Alfattah, M. S., Tradisi Upacara Ogoh-Ogoh... 289-300; Bettaliyah, A. A., \& Mubin, M., Peta Desa Wisata Budaya... 1448-1454. 
Chambers, R., PRA (Participatory Rural Appraisal): Memahami Desa secara Partisipatif (edisi terjemahan), Yogyakarta: Kanisius, 1996.

Chin, C. Law, F. Y., Lo, M. C., \& Ramayah, T, "The Impact of Accessibility Quality and Accommodation Quality on Tourists' Satisfaction and Revisit Intention to Rural Tourism Destination in Sarawak: The Moderating Role of Local Communities' Attitude", Global Business and Management Research: An International Journal, Vol. 10, No. 2, pp. 115-127, 2018. https:// www.researchgate.net/publication/328899252

Cresswell, J. W., Research Design: Qualitative, Quantitative, and Mixed Methods Approaches(4th edition), Thousand Oaks, California: SAGE Publication Inc, 2013.

Dinas Pariwisata Kabupaten Lamongan. (2020). Pemerintah Kabupaten Lamongan. https://lamongankab.go.id/disparbud/files/2020/03/JML-KNIUNGAN-WISATAGRAFIK.pdf (diakses 2020)

Ewen, C. J., Hoffer, M. R., Capobianco, M. C., \& Doucette, R. M., Community-Based Inclusion: Promoting Rural Tourism Through Accessibility in Cuenca, Ecuador. Worcester Polytechnic Institute: Interactive Qualifying Projects, 2019. https:// digitalcommons.wpi.edu/iqp$\underline{\text { all } / 5497}$

Gomezelj, D. O., "A Systematic Review of Research on Innovation in Hospitality and Tourism", International Journal of Contemporary Hospitality Management, Vol. 28, No. 3, pp. 516-558, 2016. https:// doi.org/10.1108/IJCHM-10-2014-0510

Google Maps (diakses 2020).

Holloway, J., Humphreys, C., \& Davidson, R., The Business of Tourism, 8th Edition, England: Pearson Education Limited, 2009.

Ismail, Titofianti, A. A., \& Nurany, F., “Desain Persatuan dan Kesatuan sebagai Ikon Desa Wisata Religi di Desa Balun Kecamatan Turi Kabupaten Lamongan Jawa Timur", Governance: Jurnal Manajemen dan Kebijakan Publik, Vol. 9, No. 1, pp. 57-63, 2019. http://jurnal.fisip-uwp.ac.id/index.php/governance/article/view/31/24

Kecamatan Turi dalam Angka 2018. (2018). BPS Kabupaten Lamongan. https:/ / lamongankab.bps.go.id/publication/2018/09/26/7c25d057b8504b87a454ce51 /kecamatan-turi-dalam-angka-2018.html

León, C. J., Hernández, J. M., \& González, M., “Economic Welfare, The Environment and The Tourist Product Life Cycle", Tourism Economics, Vol. 13, No. 4, pp. 583-601, 2007. https://doi.org/10.5367/000000007782696078

Litvin, S., Goldsmith, R., \& Pan, B.,"'A Retrospective View of Electronic Word-of- Mouth in Hospitality and Tourism Management", Journal of Contemporary Hospitality Management, Vol. 30, No. 1, pp. 313-325, 2018. https://doi.org/10.1108/IJCHM-082016-0461 
Meler, M., \& Cerović, Z., "Food Marketing in The Function of Tourist Product Development", British Food Journal, Vol. 105, No. 3, pp. 175-192, 2003. https://doi.org/10.1108/00070700310477

Naskah Akademik Rencana Tata Ruang dan Tata Wilayah Kabupaten Lamongan. (2020). Pemerintah Kabupaten Lamongan. http://lamongankab.go.id/instansi/wpcontent/uploads/sites/31/2013/08/Bab-06-Penetapan-Kawasan-Strategis_2012.pdf

Rosli, M.M, \& Syamsuriana, S., “The Impact of Innovation on The Performance of Small and Medium Manufacturing Enterprises: Evidence of Malaysia", Journal of Innovation Management in Small and Medium Enterprises, Vol. 2013, 2013. https://doi.org/10.5171/2013.885666

Sanchez, P. S., \& Dorta, A. V., "Drivers of Airport Scheduled Traffic in European Winter Tourism Areas: Infrastructure, Accessibility, Competition and Catchment Area", Journal of Transport Air Management, Vol. 81, pp. 1-11, 2019. https://doi.org/10.1016/j.jairtraman.2019.101723

Sugiyono, Metode Penelitian Kuantitatif, Kulitatif, dan RED, Bandung: Alfabeta, 2012.

Supriatna, A., "Relevansi Metode Participatory Rural Appraisal dalam Mendukung Implementasi Undang-Undang Pemerintahan Desa", Jurnal Lingkar Widyaiswara, Vol. 1, No. 1, pp. 39-45, 2014. http://juliwi.com/published/E0101/Paper0101_39-45.pdf Taghizadeh, S.K, \& Syed, A.R., “The Effect of Service Product Innovation Management on Market Performance", International Journal of Business an Innovation, Vol I, No. 1, pp. 115, 2013. https:// www.researchgate.net/publication/271666441

Tamayo, J.A., Garcia, J.E.R., \& Roman, J.A., “Do Innovation and Cooperation Influence SMEs Competitiveness? Evidence from The Andalusian Metal-Mechanic Sector", Innovar Journal, Vol. 25 , No. 5, pp. 101-115, 2014. https://doi.org/10.15446/innovar.v25n55.47226

Taylor, S. J., Bogdan, R., \& DeVault, M., Introduction to Qualitative Research Methods: A Guidebook and Resource, New Jersey: John Wiley \& Sons, 2015.

Ulum, K., “Budaya Toleransi: Studi Living Islam di Desa Balun, Lamongan”, Living Islam: Journal of Islamic Discourses, Vol. II , No. 1, pp. 143-168, 2019. http://ejournal.uinsuka.ac.id/ushuluddin/li/article/view/1881

Vanhove, N., The Economics of Tourism Destinations, Great Britain: Elsevier ButterworthHeinemann, 2005. 